\title{
Hospital Payment Based On Diagnosis-Related Groups Differs In Europe And Holds Lessons For The United States
}

ABSTRACт England, France, Germany, the Netherlands, and Sweden spend less as a share of gross domestic product on hospital care than the United States while delivering high-quality services. All five European countries have hospital payment systems based on diagnosis-related groups (DRGs) that classify patients of similar clinical characteristics and comparable costs. Inspired by Medicare's inpatient prospective payment system, which originated the use of DRGs, European DRG systems have implemented different design options and are generally more detailed than Medicare's system, to better distinguish among patients with less and more complex conditions. Incentives to treat more cases are often counterbalanced by volume ceilings in European DRG systems. European payments are usually broader in scope than those in the United States, including physician salaries and readmissions. These European systems, discussed in more detail in the article, suggest potential innovations for reforming DRG-based hospital payment in the United States.

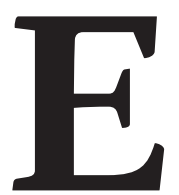
uropean countries often look to the United States for inspiration and innovation in ways of organizing and paying for health care. One prominent example of US innovation was the Medicare inpatient prospective payment system introduced in 1983 in the United States.

The basic idea of the system was to classify hospital cases into diagnosis-related groups (DRGs) of patients with similar clinical characteristics and comparable costs, and to pay hospitals a flat fee for each DRG that reflected national average treatment costs of patients in that grouping. At the time, this idea was revolutionary, and it was adopted by countries around the world. Consequently, DRG-based hospital payment systems gradually emerged as the principal means of paying for hospital care in most developed countries, ${ }^{1}$ particularly in Europe. ${ }^{2}$

The United States has now embarked on another quest to identify innovative payment models that will contribute to better health care at lower costs. The recently established Center for Medicare and Medicaid Innovation, a branch of the Department of Health and Human Services, is a primary player in that pursuit. However, US payment reform efforts might also benefit from a look at how payment systems originally inspired by Medicare have developed abroad.

European countries such as England, France, Germany, the Netherlands, and Sweden spend less on hospital care than the United States, both per capita and as a percentage of gross domestic product (GDP) (see Exhibit A1 in the online Appendix).$^{3-5}$ At the same time, these countries deliver high-quality care in hospitals. They score similarly to the United States on a long list of quality indicators, and most of them do not have waiting times for care that are any longer than in the United States. ${ }^{6,7}$

We analyzed hospital payment systems in
DOI: 10.1377/hlthaff.2012.0876 HEALTH AFFAIRS 32 , NO. 4 (2013): 713-723 (c)2013 Project HOPEThe People-to-People Health Foundation, Inc
Wilm Quentin (wilm.quentin@ tu-berlin.de) is a senior research fellow in the Department of Health Care Management at the Berlin University of Technology and a research fellow of the European Observatory on Health Systems and Policies, in Germany.

David Scheller-Kreinsen is an economic adviser in the Hospital Division of the National Association of Sickness Funds, in Berlin, Germany.

Miriam Blümel is a research fellow in the Department of Health Care Management at the Berlin University of Technology.

Alexander Geissler is a research fellow in the Department of Health Care Management at the Berlin University of Technology.

Reinhard Busse is a professor and the department head for health care management in the Faculty of Economics and Management at the Berlin University of Technology and the associate head for research policy at the European Observatory. 
Europe based on a conceptual framework that was originally developed by Randall Ellis and Mark Miller, ${ }^{8}$ which we expanded for our purposes. We used this framework to highlight differences between European hospital payment systems and Medicare's inpatient prospective payment system. In doing so, we summarized the results of EuroDRG, a large European research project comparing DRG-based hospital payment systems in Europe.

The framework by Ellis and Miller highlights the principles underlying different provider payment mechanisms and facilitates an understanding of how countries pay for hospital services. It consists of five dimensions for analysis that apply to all payment systems: the basis of information for determining hospital payments; the scope of payments; the adequacy of payments; the fineness of payments, or whether a system reflects different levels of severity in patient illnesses; and quality, or whether the payment system provides incentives for delivering high-quality health care services.

\section{European DRG-Based Hospital Payment Systems}

It is unlikely that any hospital payment system will ever be able to align perfectly the interests of payers, patients, and providers. ${ }^{9}$ We do not pretend that the features of hospital payment systems in England, France, Germany, the Netherlands, and Sweden necessarily make those systems better than Medicare's inpatient prospective payment system. However, we believe that numerous features and innovations of European hospital payment systems can serve as models of better ways of paying for hospital care in the United States.

In England, France, Germany, the Netherlands, and Sweden DRG-based hospital payment systems were introduced between 1995 and 2005-one or two decades after the introduction of the Medicare inpatient prospective payment system (Exhibit 1). In Europe the dominant provider payment mechanisms prior to the introduction of DRGs were systems of global budgets or spending limits, with adjustments for activity-for example, in terms of

EXHIBIT 1

\begin{tabular}{|c|c|c|c|c|c|c|}
\hline & England & France & Germany & Netherlands & Sweden & US (IPPS) \\
\hline \multicolumn{7}{|c|}{ BASIC CHARACTERISTICS OF DRG-BASED HOSPITAL PAYMENT SYSTEMS } \\
\hline $\begin{array}{l}\text { Patient classification } \\
\text { system }\end{array}$ & $\begin{array}{l}\text { Healthcare } \\
\text { Resource } \\
\text { Group (HRG) }\end{array}$ & $\begin{array}{l}\text { Groupe } \\
\text { Homogène de } \\
\text { Malades (GHM) }\end{array}$ & $\begin{array}{l}\text { German DRG } \\
\text { (G-DRG) }\end{array}$ & $\begin{array}{l}\text { Diagnose } \\
\text { Behandeling } \\
\text { Combinaties } \\
\text { (DBC) }\end{array}$ & NordDRG & $\begin{array}{c}\text { Medicare severity } \\
\text { DRG (MS-DRG) }\end{array}$ \\
\hline Year introduced & 2003 & 1996 & 2003 & 2005 & 1995 & 1983 \\
\hline Prior payment system & $\begin{array}{l}\text { Global budget } \\
\text { (with activity } \\
\text { adjustment) }\end{array}$ & $\begin{array}{l}\text { Global budget } \\
\text { (with activity } \\
\text { adjustment) }\end{array}$ & $\begin{array}{l}\text { Global budget } \\
\text { (with activity } \\
\text { adjustment) }\end{array}$ & $\begin{array}{l}\text { Global budget } \\
\text { (with activity } \\
\text { adjustment) }\end{array}$ & $\begin{array}{l}\text { Global budget } \\
\text { (with activity } \\
\text { adjustment) }\end{array}$ & Fee-for-service \\
\hline Frequency of revisions & Annual & Annual & Annual & Irregular & Biennial & Annual \\
\hline Applied to & $\begin{array}{l}\text { All hospitals } \\
\text { treating NHS } \\
\text { in- and } \\
\text { outpatients }\end{array}$ & $\begin{array}{l}\text { All hospitals, } \\
\text { in- and } \\
\text { outpatients }\end{array}$ & $\begin{array}{l}\text { All hospitals, } \\
\text { in- and } \\
\text { outpatients }\end{array}$ & $\begin{array}{l}\text { All hospitals, } \\
\text { in- and } \\
\text { outpatients }\end{array}$ & $\begin{array}{l}\text { Depending on } \\
\text { county, in- and } \\
\text { outpatients }\end{array}$ & $\begin{array}{l}\text { All hospitals } \\
\text { treating Medicare } \\
\text { patients (some } \\
\text { exceptions) }\end{array}$ \\
\hline \multicolumn{7}{|c|}{ BASIS OF INFORMATION FOR PAYMENTS ${ }^{b}$} \\
\hline Patient characteristics & Yes & Yes & Yes & Yes & Yes & Yes \\
\hline $\begin{array}{l}\text { Service characteristics } \\
\text { Provider characteristics }\end{array}$ & Yes & Yes & Yes & Yes & Yes & Yes \\
\hline $\begin{array}{l}\text { Volume of activity } \\
\text { (such as global budget) }\end{array}$ & $\begin{array}{l}\text { No (but plans } \\
\text { exist for } \\
\text { volume cap) }\end{array}$ & No & $\begin{array}{l}\text { DRG-based } \\
\text { budgets }\end{array}$ & $\begin{array}{l}\text { Budgets for } \\
30 \% \text { of DRGs }\end{array}$ & $\begin{array}{l}\text { Volume ceilings } \\
\text { or budgets }\end{array}$ & No \\
\hline $\begin{array}{l}\text { Location (such as } \\
\text { market forces factor) }\end{array}$ & Yes & Yes & Yes & No & Yes & Yes \\
\hline
\end{tabular}

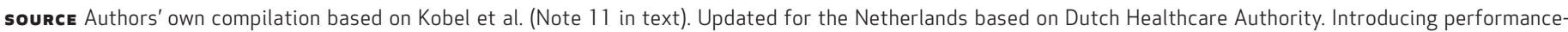

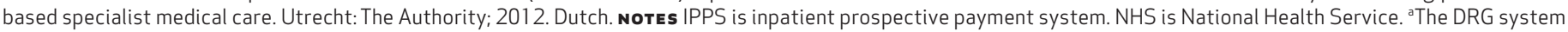

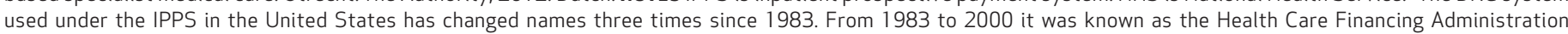

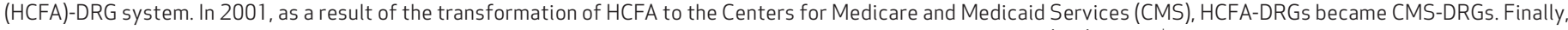

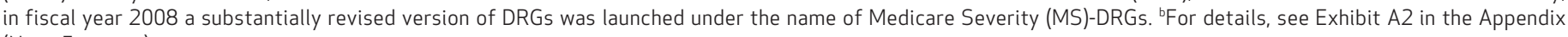
(Note 5 in text). 
number of patients, procedures, or total inpatient days.

The primary purpose of moving toward DRGs in Europe was to increase the transparency and productivity of hospitals. ${ }^{10}$ For example, DRGs can increase transparency about hospitals' workloads by uncovering the fact that one hospital treats more complex cases than another-that is, that cases in one hospital fall, on average, into more costly DRGs than in another. DRGs can improve transparency about hospital resource use by exposing the fact that patients in the same DRGs are staying markedly longer (or are more costly) in one hospital than in another. Productivity is thought to increase because hospitals are paid on the basis of the number and types of patients treated, which provides incentives for them to treat a lot of patients while limiting the amount of resources used for treatment.

Today England and the Netherlands use DRG systems that they developed from scratch, while France, Germany, and Sweden have DRG systems that were originally imported from the United States or Australia and later adjusted to meet country-specific needs. ${ }^{11}$ The DRG systems have all been revised several times since their introduction, and they show considerable heterogeneity in how individual patients are allocated into DRGs. ${ }^{12-14}$

We explain these different systems below, and we draw comparisons to the situation in the United States, where the DRG system has been revised annually and has changed names several times since 1983. In fiscal year 2008, following a very major restructuring of the grouping logic, Medicare's DRG system was renamed Medicare Severity-DRGs (MS-DRGs).

The DRG-based hospital payment system is the single most important payment mechanism in each of the five countries we studied. Approximately 60-85 percent of total hospital revenues flow through DRG-based hospital payment systems. These systems are the standard modality of paying for care at both public and private hospitals and cover both inpatients and day cases-patients formally admitted to the hospital for minor surgery who leave the hospital either the same day or within twenty-four hours. ${ }^{15}$

European DRG classification systems are applied to all patients, independent of their insurer or insurance status. Hospitals thus cannot shift costs to or fulfill their revenue expectations through patients with different payment modalities.

An important point is that in Europe, unlike in the United States, DRG-based payments often exist within a global budget that is usually set at the hospital level. There is no such overall budget for hospital inpatient payment under US Medicare. In addition, in Europe there may be separate global budgets for specific areas of care, such as mental health, and additional payments are available for certain services, such as treatment in intensive care units in England.

BASIS OF INFORMATION By way of background, payments of any type in health care can be defined based on provider, service, or patient characteristics or combinations of these. The basis of information for determining payments has an important influence on the incentives of the payment system.

For example, global budgets that are primarily based on provider characteristics, such as the number of available beds or types of specialties, ensure the availability of infrastructure but do not reward productivity, since those who provide more services will not be paid more for them. Fee-for-service systems, in contrast, encourage the provision of services but may lead to overprovision. Payment systems based on patient characteristics, such as diagnosis or age, provide incentives to treat a high number of patients while keeping costs per patient at a minimum.

All hospital payment systems based on DRGs take into account information about patient diagnoses, service characteristics (the particular procedures performed, such as heart or cancer surgeries), and other patient characteristics for a more balanced set of incentives. ${ }^{16}$

The basis of information for all DRG-based hospital payment systems in Europe is determined by the classification variables used for grouping patients into DRGs and by limits on the volume of activity, such as global budgets, and adjustment factors related to location or market forces. DRG systems in Europe rely mostly on patient and service characteristics that are also used in Medicare's MS-DRGs (Exhibit 1; also see Exhibit A2 in the Appendix for more details)..$^{5,17}$

However, in several European DRG-based payment systems, service characteristics play a more prominent role in the classification process. In England's Health Care Resource Groups, service characteristics are considered before patient characteristics such as diagnoses in the classification process. ${ }^{11}$ In Germany the number of surgical DRGs has increased substantially since the introduction of the system in 2003.

Hospital payment in most countries depends on all three types of information-patient, provider, and service characteristics-as integral parts of the system. The excessive expansion of activity-a potential negative consequence of a strong link between service provision and payment received-is counterbalanced in Germany, 
the Netherlands, and Sweden by the existence of provider-level targets or budgets that limit to a certain extent the revenues that hospitals can receive through DRG-based payments.

For example, in Germany the total volume of services that a hospital is targeted to provide is negotiated each year between sickness fundsentities fulfilling the role of insurer in the German system-and hospitals. If a hospital exceeds this target, the DRG-based payment is reduced by a certain percentage. The payment is increased if the hospital remains below the target. However, this mechanism did not stop the expansion of certain apparently more lucrative services such as hip implants, ${ }^{18}$ because only the total volume of hospital services is limited, not specific activities.

SCOPE of hospital payments The scope of hospital payments refers to the level of aggregation or "bundling" of services in the DRG system-within providers or across providers and over time. Hospitals in most European countries receive one DRG-based payment for each admitted patient that covers all costs of services during a hospital stay, similar to Medicare's inpatient prospective payment system (Exhibit 2).
However, unlike in that system, the scope of payments in European countries often extends beyond twenty-four hours after discharge.

For example, since 2004 hospitals in Germany receive only a single DRG-based payment that includes costs for readmission to hospitals for the same reason either within certain time limits defined per DRG or within thirty days after the initial admission. In Sweden, where county governments determine the modalities of DRG use, hospitals in Stockholm County do not receive a second payment for hip or knee replacement patients readmitted for complications from surgery within two years after discharge.

In addition, the scope of payment in Europe usually also includes physician salaries or fees. In most countries all services provided in hospitals by surgeons, anesthesiologists, radiologists, and others are covered by the DRG-based payment to the hospital, although exceptions exist in France and Germany (Exhibit 2).

In the Netherlands physician fees for care provided in the hospital have been included within hospital payments since the introduction of the Dutch system in 2008. Almost all countries include hospital capital costs within the DRG

EXHIBIT 2

\begin{tabular}{|c|c|c|c|c|c|}
\hline \multicolumn{6}{|c|}{ Scope Of Hospital Payment In 5 European Diagnosis-Related Group (DRG)-Based Systems } \\
\hline & England & France & Germany & Netherlands & Sweden \\
\hline $\begin{array}{l}\text { Payments per } \\
\text { hospital stay }\end{array}$ & One & One & One & Several possible & One \\
\hline $\begin{array}{l}\text { DRG extends } \\
\text { until }\end{array}$ & $\begin{array}{l}30 \text { days after } \\
\text { discharge } \\
\text { (for elective } \\
\text { admissions) }\end{array}$ & $\begin{array}{l}30 \text { days after } \\
\text { admission } \\
\text { or until upper } \\
\text { outlier limit }\end{array}$ & $\begin{array}{l}30 \text { days after } \\
\text { admission or until } \\
\text { upper outlier limit }\end{array}$ & $\begin{array}{l}42 \text { days after discharge } \\
\text { (for inpatient } \\
\text { admission) or } \\
42 \text { days after } \\
\text { outpatient treatment }\end{array}$ & $\begin{array}{l}\text { Day of discharge } \\
\text { (except in certain } \\
\text { counties-for } \\
\text { example, two } \\
\text { years for certain } \\
\text { groups of patients } \\
\text { in Stockholm) }\end{array}$ \\
\hline \multicolumn{6}{|c|}{ SCOPE OF PAYMENT INCLUDES: } \\
\hline Recurrent costs & Yes & Yes & Yes & Yes & Yes \\
\hline Physician fees & Yes & $\begin{array}{l}\text { Yes-in public hospitals } \\
\text { No-in private hospitals }\end{array}$ & $\begin{array}{l}\text { Yes (except for } 5 \% \text { of } \\
\text { cases treated by } \\
\text { practice-based } \\
\text { physicians) }\end{array}$ & Yes & Yes \\
\hline Capital costs & Yes & Yes (but not all) & No (only some) & Yes & Yes \\
\hline \multicolumn{6}{|c|}{ OUTSIDE THE SCOPE OF PAYMENT, ADDITIONAL PAYMENTS FOR: } \\
\hline $\begin{array}{l}\text { Specific high- } \\
\text { cost } \\
\text { services }\end{array}$ & $\begin{array}{l}\text { Unbundled HRGs for } \\
\text { chemotherapy, } \\
\text { radiotherapy, } \\
\text { high-cost drugs, } \\
\text { and ICU care }\end{array}$ & $\begin{array}{l}\text { Séances GHM for } \\
\text { chemotherapy and } \\
\text { radiotherapy; } \\
\text { additional payments } \\
\text { for emergency care, } \\
\text { high-cost drugs, and } \\
\text { ICU care }\end{array}$ & $\begin{array}{l}\text { Supplementary } \\
\text { payments } \\
\text { for chemotherapy, } \\
\text { radiotherapy, and } \\
\text { high-cost drugs }\end{array}$ & $\begin{array}{l}\text { Yes (since 2012) for } \\
\text { ICU care, and } \\
\text { provided in } \\
\text { cooperation with } \\
\text { practice-based } \\
\text { physicians }\end{array}$ & $\begin{array}{l}\text { Cost-outlier payments } \\
\text { for cases above a } \\
\text { threshold; } \\
\text { additional } \\
\text { payments for burns } \\
\text { and high-cost drugs }\end{array}$ \\
\hline $\begin{array}{l}\text { Innovation- } \\
\text { related } \\
\text { payments }\end{array}$ & Yes & Yes & Yes & $\begin{array}{l}\text { Yes (for expensive } \\
\text { orphan drugs) }\end{array}$ & Yes \\
\hline
\end{tabular}

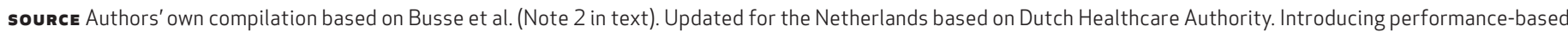

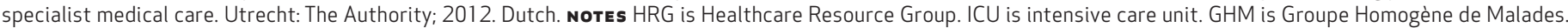


payment. The exception is Germany, where investment funding for hospitals is provided by the states. Consequently, the scope of hospital payment systems in many European countries is broader than in the United States.

The potentially negative consequences of a broader scope in hospital DRG payments, such as skimping on services that cannot be billed separately, are probably counterbalanced in Europe by additional payments for certain high-cost services. For example, in England, Germany, and France, chemotherapy, radiotherapy, renal dialysis, high-cost drugs, devices, and some other services are reimbursed separately through additional payments on top of the basic DRG-based payment. All systems have developed mechanisms to provide additional payments for certain innovative technologies, including drugs, when they are not adequately reimbursed through the payment system. ${ }^{19}$

ADEQUACY OF hOSPITAL PAYMENTS If DRGbased payments to hospitals are too low to cover treatment costs, providers will attempt to reduce costs by cutting services or reducing quality. If payments are too high, providers have no incentive to behave efficiently and will waste resources. In most European countries the size of payment per DRG is calculated by multiplying a payment rate or weight that is an indicator of the costs of care for patients in that DRG-higher weights for more costly DRGs-with a base payment or base rate that might vary depending on the location of the hospital to account for differences in production costs.

In most European countries DRG systems calculate weights differently than does the Centers for Medicare and Medicaid Services (CMS), the US agency that oversees the MS-DRG. CMS calculates weights on the basis of charges from Medicare claims and costs reported in hospitals' Medicare cost reports. ${ }^{17}$ To calculate "costbased" weights, CMS applies nationally uniform cost-to-charge ratios.

Exhibit 3 summarizes information about the collection of cost data used to determine hospital payment rates in Europe. England, France, Germany, the Netherlands, and Sweden collect data about costs of service provision in hospitals, but the size of the data sample and the quality of cost data vary among countries.

England mandates that all National Health Service (NHS) hospitals provide cost accounting

EXHIBIT 3

Adequacy Of Hospital Payment Rates And Fineness Of Categories Of Diagnosis-Related Groups (DRGs) In 5 European Systems

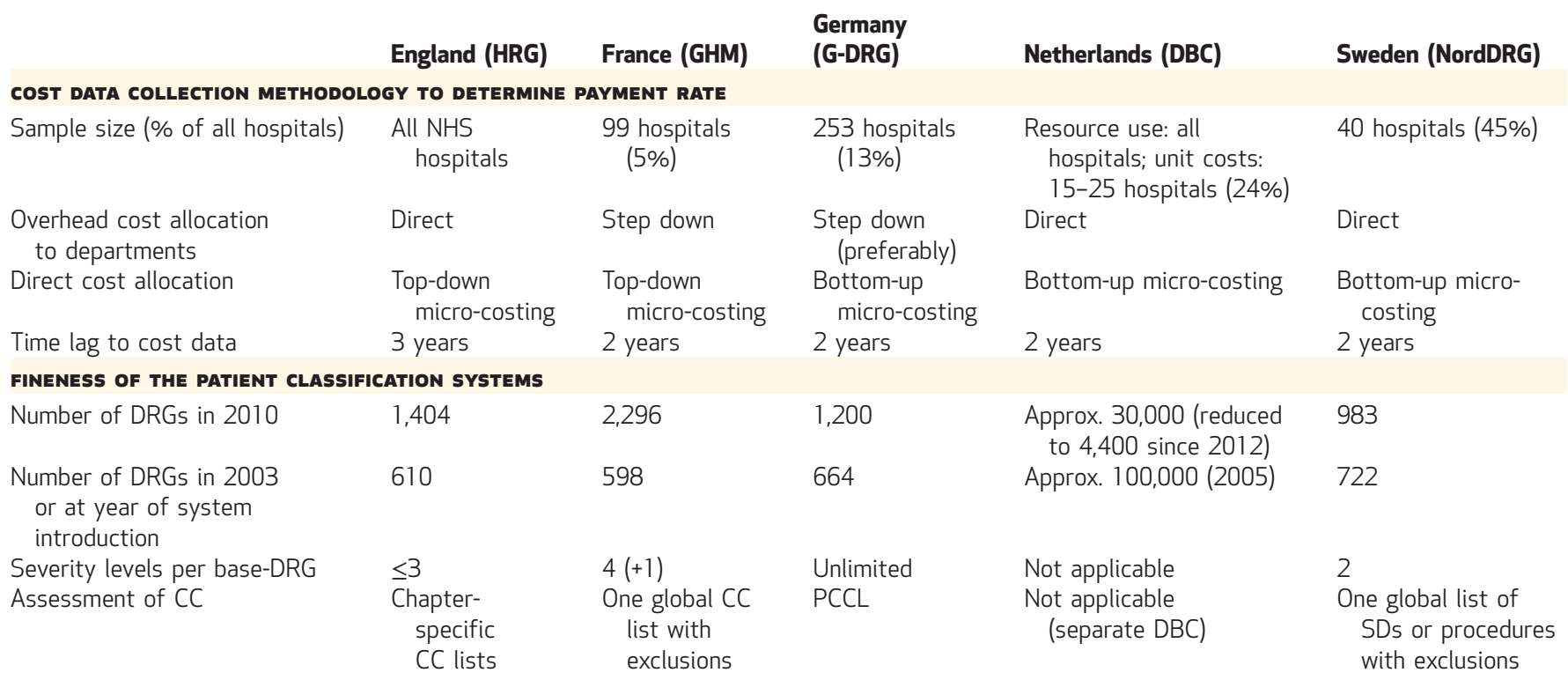

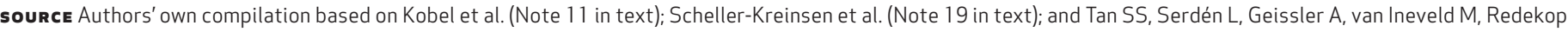

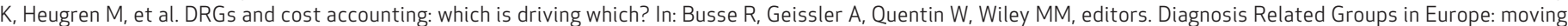

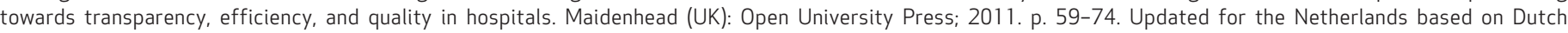

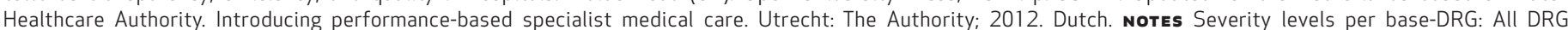

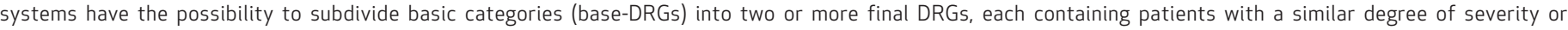

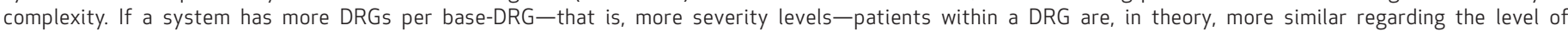

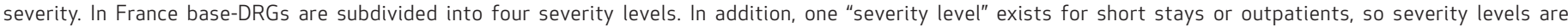

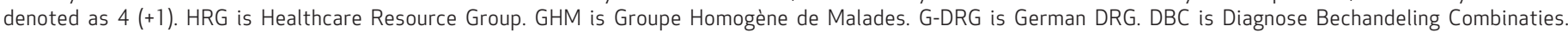
NHS is National Health Service. CC is complication and comorbidity. PCCL is Patient Cumulative Complexity Level. SD is secondary diagnosis. 
data to a national database-a requirement similar to the CMS requirement that hospitals treating Medicare patients submit an annual cost report. France, Germany, the Netherlands, and Sweden use data from only a sample of hospitals that follow a standardized cost accounting approach, employing a detailed bottom-up costing methodology to calculate costs of treating individual patients.

The time lag between collection of cost data and the use of this information for setting DRG payment rates differs across countries. The system in England relies on DRG weights based on cost data that are three years old, similar to the MS-DRG system in the United States, where weights are based on three-year-old cost dataalthough they are multiplied using two-year-old claims data. In the other four countries the time lag between collection of cost data and determination of payment rates is two years. ${ }^{19}$

There is a trade-off between collecting highquality cost accounting information and ensuring that a large and representative sample of hospitals contribute to a national cost database. ${ }^{20}$ The Netherlands has struck a balance between representativeness and data quality by collecting data on resource use from all hospitals and data on unit costs from a small sample of hospitals. ${ }^{21}$

Because collecting detailed cost accounting information requires additional work by hospitals, regulatory authorities in some countries have started to pay hospitals for participating in the cost accounting data sample. For example, in Germany hospitals receive a fixed allowance for participating in the cost data sample and a variable amount that depends on the number of patients, with high-quality cost data submitted to the database. ${ }^{10}$

One innovation related to the adequacy of payment to hospitals is the so-called best-practice tariffs in England. (The price schedule for DRGs is called the tariff schedule, so these tariffs are the rates that the NHS pays hospitals.) For certain high-volume DRGs, about which clear consensus exists regarding best practice-for example, hip fracture or stroke-hospital payments are no longer based on average costs but on costs of providing care that is in line with clinical guidelines. ${ }^{22}$ Depending on the condition, payments to hospitals for best-practice tariffs may be above or below average costs of current care in hospitals. For example, for stroke care, guidelines request treatment on a stroke unit, brain imaging within specified time limits, and assessment for thrombolysis, and the best-practice tariff for hospitals complying with the guideline is set higher than average costs. In contrast, for primary hip and knee replacement, all hospitals receive a tariff that is below national average costs, with the rationale being that providers using enhanced recovery principles have lower costs.

FINENESS OF PAYMENTS In all payment systems, a "fine" hospital payment system is one with many different payment categories, whereas a "coarse" payment system incorporates only a few payment categories. For DRG-based systems, if the hospital payment system is not sufficiently fine to account for differences among patients, hospitals treating relatively sicker patients are not adequately reimbursed for their efforts. At the same time, hospitals treating patients with less complex conditions may be overpaid for their services.

In 2010 the number of DRGs in most European systems was higher than in Medicare's MSDRG system. The number of DRGs ranged from 983 in Sweden to about 2,300 in France; the Netherlands was an extreme outlier with 4,400 as of 2012 (Exhibit 3).

Medicare's MS-DRG system, with 751 groups in 2013, has more groups than the older DRG system had, to better account for differences in the level of complications and comorbidities of treated patients. However, European countries, excepting Sweden until 2012, have increased the number of DRGs even more since 2003 to improve adjustments for severity of illness in their DRG systems.

In the German G-DRG system, the number of severity levels per basic category, base-DRG, isin principal-not limited, and up to nine levels are now used. Thus, base-DRGs are subdivided into as many DRGs as is necessary to achieve relative homogeneity of resource consumption within each group. For example, base-DRG L63infection of the urinary system-in the 2013 version of G-DRGs is subdivided into six DRGs according to the presence of very severe complications (yes/no), treatment of multidrugresistant pathogens (yes/no), and age ( $<3$ years, 3-5 years, $>5$ years).

To assess complication and comorbidity in the classification system, several European countries rely on a list that defines a specific complication and comorbidity level for every secondary diagnosis. An individual patient's severity level is determined by the secondary diagnosis with the highest complication and comorbidity level, while taking into account certain exclusion criteria that depend on primary diagnoses or procedures.

Some European countries have further developed this system, building on work done in Australia. For example, in Germany the G-DRG classification system calculates a patient cumulative complexity level on the basis of all relevant 
secondary diagnoses, sex, and reason for discharge, such as leaving the hospital against medical advice.

HEALTH SERVICE QUALITY In Europe, England is the country that has taken the most systematic approach to incorporating quality into hospital payment. One mechanism for doing so is the Commissioning for Quality and Innovation payment framework, which allows local purchasers of hospital care to link a modest nationally fixed proportion of providers' income to the achievement of certain quality goals. ${ }^{23}$

In 2013-14 this proportion is set to 2.5 percent of the total financial volume of providers' contracts, with 0.5 percent being conditional upon achieving four nationally uniform quality goals and 2 percent to be linked to other realistic, locally agreed-upon goals. National goals could include improving dementia care and avoiding venous thromboembolism, while locally agreed goals could include reducing hospital-acquired infections, reducing the incidence of pressure ulcers, increasing the percentage of women having spontaneous vaginal delivery, and improving patients' satisfaction with hospital services.

Another mechanism for incorporating quality into payment is the best-practice tariffs, which may provide higher payments per case if hospitals adhere to agreed-upon standards. For example, for hip fracture surgery patients, quality standards mandate that patients receive surgery within thirty-six hours; be provided with multidisciplinary rehabilitation; and be screened for secondary prevention of complications, including falls and bone health assessment.

Other European countries rarely adjust DRGbased payments explicitly to provide incentives for higher quality performance. Most aim to ensure the provision of high-quality health services through other mechanisms, such as quality controls, minimum volume thresholds, and separate quality-related payments.

\section{Lessons For The United States}

The success of hospital payment reform in achieving better quality of care at a lower cost depends in part on factors that go beyond the design features of the payment system. European hospitals are embedded in a different institutional context than are US hospitals, and purchaser-provider relationships differ from one European country to another. The degree of integration of health care providers, the level of competition between providers, the ways of contracting with hospitals, negotiations for health care service volume limits, and mechanisms for monitoring providers' behavior and quality of care are determined by country- specific arrangements.

However, our analysis of hospital payment systems in five European countries suggests that experiences from Europe can inform hospital payment reform in the United States. For an overview of design options to improve hospital payment systems, and highlights of different examples of implemented options from Europe, see Exhibit 4.

European DRG-based hospital payment systems have a broader basis of information to set payment rates than Medicare's MS-DRGs have. The European DRG systems combine all three types of information-provider, service, and patient characteristics-to determine payment and provide a more balanced set of incentives. Several European DRG systems have a stronger orientation toward service characteristics than do MS-DRGs, which is further enhanced by additional payments for certain high-cost services.

This stronger orientation to patient characteristics is often counterbalanced by global revenue control measures for service delivery. Revenue constraint measures are not now part of Medicare's hospital payment system. However, the existence of DRG-based budget constraints and the use of volume adjusters to DRG-based tariffs in one state, Maryland, which uses DRGs as the basis of its all-payer system for hospital inpatient care, provide evidence of the potential for using such mechanisms in the United States to contribute to better cost control. ${ }^{24}$

Hospital payment systems in Europe are broader in scope than Medicare's MS-DRGs are. European systems incorporate more types of costs and longer time frames for services that extend several weeks after discharge. One DRGbased payment generally covers all services provided in hospitals, including physician salaries or fees.

In the United States almost 20 percent of Medicare beneficiaries discharged from hospitals are readmitted within thirty days, ${ }^{25}$ mostly without ever having seen a physician after discharge. In most European countries hospitals would not receive a second DRG-based payment for readmissions within this period of time. Consequently, hospitals have strong incentives to improve their discharge arrangements. The United States is taking another tack to discourage readmissions. As of 2012 its Medicare program has begun penalizing hospitals that have readmission rates above certain thresholds for three conditions-heart attack, congestive heart failure, and pneumonia-and the penalty system will be expanded to more conditions over time.

In Germany a thirty-day readmission rule prevents hospitals, under certain conditions, from receiving a second payment for readmitted 
Design Options To Improve Hospital Payment Systems, With Examples From Europe

Design options to improve

Framework dimension hospital payment (theory)

Information basis Diversify the information basis: to provide a balanced set of incentives

Scope of payment

Combine a broad scope of payment with add-on payments: to make providers responsible for all costs of care, including after discharge, and to encourage delivery of priority services
Adequacy of payment
Improve payment adequacy, so hospitals are adequately reimbursed for services they provide
Pay hospitals on the basis of what it costs to deliver efficient and high-quality care, to reflect care in line with clinical guidelines

\section{Examples from Europe}

England and Germany: stronger procedure orientation of DRG systems than in the US; add-on payments to reduce skimping incentives of DRG-based payments

Germany, Netherlands, and Sweden: provider-level budgets or volume ceilings to balance incentives for expansion of activity

All countries (except Sweden): broad time scope: DRG payment includes readmissions within 30 days (or 42 days in the Netherlands)

All countries: broad scope: physician salaries are included in DRG-based payments

All countries: narrow scope: add-on payments for certain high-cost priority services on top of DRG-based payments

Germany, Netherlands, and Sweden: standardized bottom-up cost data collection in (a sample of) hospitals for reliable cost-weight calculation

All countries (except England): two-year time lag between data collection and payment, to ensure that payments are in line with current practice (instead of three years as in the US).

England: best-practice tariffs: encourage efficiency and quality by setting payments at costs of providing care in line with clinical guidelines (may be above or below average costs)

All countries (except Sweden): finer payment systems than in the US

Germany: possibly better adjustment for severity of illness through calculation of Patient Cumulative Complexity Level

England: CQUIN payment framework links $2.5 \%$ of provider contracts to achievement of a set of locally agreed quality measures

England: best-practice tariffs for certain conditions: higher payments for providers if they adhere to agreed-upon quality standards

SOURCE Authors' own compilation. Notes DRG is diagnosis-related group. CQUIN is Commissioning for Quality and Innovation.

patients. This rule contributed to a strong reduction in readmissions within 30 and 360 days after discharge since its introduction in $2004 .^{26}$ The broader scope of hospital payment in European countries resembles to a certain degree Medicare's Acute Care Episode Demonstration project, ${ }^{27}$ and the experiences of European countries might encourage CMS to proceed in this direction.

In Germany, the Netherlands, and Sweden detailed and highly standardized bottom-up cost accounting information from a sample of hospitals is used to calculate adequate payment rates. Regulators in these countries do not need to worry about distortions that result from nationally uniform cost-to-charge ratios for the calculation of cost weights, such as those used by CMS.

European countries often use more recent data for cost weight calculation than CMS uses. In England the innovative approach known as best-practice tariffs ${ }^{22}$ bases reimbursement for certain conditions on the costs of providing care that is in line with clinical guidelines, instead of average costs.

Adjustments for severity of illness in European DRG systems are possibly better than those in the United States, even though MS-DRGs represent an improvement over the earlier US DRG system. ${ }^{28}$ In Europe it is more difficult for hospitals to specialize in profitable patients than in the United States. There is no simple relationship between the number of DRGs and the ability of DRG systems to explain variation in resource consumption. ${ }^{29}$

CMS could test whether certain European approaches to adjustment for severity of illness, such as the method of calculation of patients' cumulative complexity levels in Germany, can contribute to improved severity adjustment. If CMS were to start collecting standardized patient-level cost accounting data from hospitals, the agency would also be able to revise the MSDRG system on the basis of higher-quality data. In Germany, where patient-level cost accounting data have been used to improve the system since its introduction in 2003, the ability of the system to explain variation in costs of care as measured 
through reduction in cost variance has increased by more than 60 percent. ${ }^{30,31}$

In most European countries pay-for-quality initiatives are in the early stages of development. England is the only country that explicitly adjusts hospital payment for quality of care. The Commissioning for Quality and Innovation framework and best-practice tariffs are interesting developments.

Although the Commissioning for Quality and Innovation framework has not yet been evaluated, results of the Advancing Quality program, a program in the northwest region of England that preceded the national program, have recently been published. ${ }^{32}$ Advancing Quality was organized as a tournament of participating hospitals and awarded large bonuses (up to 4 percent of the revenue for the associated activity) for improving or achieving goals in twenty-eight quality indicators covering five clinical areas (acute myocardial infarction, coronary artery bypass grafting, heart failure, hip and knee surgery, and pneumonia). The evaluation of the program found a larger reduction of mortality for the included conditions than for conditions that were not included and a larger reduction at participating hospitals when compared with other hospitals in England. The evaluation concluded that the program was associated with a clinically significant reduction in mortality. An early evaluation of the best-practice tariff for hip fracture has shown that the percentage of patients receiving care according to agreed-upon standards has increased considerably, from 24 percent in the first quarter of 2010 to
55 percent in the last quarter of $2011 . .^{33}$

Better data about quality of care in European hospitals should become available not only through improved coding of diagnoses and procedures but also through explicit quality measurement initiatives that go beyond routine documentation of diagnoses and procedures, such as the Commissioning Framework in England and the system of quality indicators elaborated in Germany. ${ }^{34}$ With such data, European countries are bound to integrate this information in their hospital payment systems.

\section{Conclusion}

European countries often look to the United States for examples of ways to organize and pay for health care. One innovation that was successfully transferred, and that has fundamentally transformed hospital payment systems in Europe, is the Medicare inpatient prospective payment system. The United States could benefit likewise from taking into consideration experiences from Europe in adapting that system.

Hospital payment systems in England, France, Germany, the Netherlands, and Sweden provide examples of ways to draw on a more diversified basis of information to determine payment, incorporate a broader scope that extends until several weeks after discharge, result in payments that more adequately reflect the cost of services, and have better adjustments for the severity of illness. These system features could provide further inspiration for hospital payment reforms already under way in the United States.
The findings presented in this article were generated in the framework of the Diagnosis-Related Groups in Europe: Towards Efficiency and Quality (EuroDRG) project. The project was funded through the seventh framework programme (FP7) of the European
Commission under Grant Agreement No. 223300. The funding source did not influence the study questions, design, data collection, analysis, or interpretation of results at any stage. The authors are grateful to all of their partners who made this work possible.
They thank Robin Osborn, Stuart

Guterman, Cathy Schoen, Tony Shih, and Bradford Gray for their helpful comments on earlier versions of the manuscript.
NOTES

1 Paris V, Devaux M, Wei L. Health systems institutional characteristics: a survey of 29 OECD countries. Paris: Organization for Economic Cooperation and Development; 2010.

2 Busse R, Geissler A, Quentin W, Wiley MM, editors. Diagnosis Related Groups in Europe: moving towards transparency, efficiency, and quality in hospitals. Maidenhead (UK): Open University Press; 2011.

3 Organization for Economic Cooperation and Development. OECD health data 2011: statistics and indicators. Paris: OECD; 2011.
4 Koechlin F, Lorenzoni L, Schreyer P. Comparing price levels of hospital services across countries: results of pilot study. Paris: OECD; 2010.

5 To access the Appendix, click on the Appendix link in the box to the right of the article online.

6 Schoen C, Osborn R, Squires D, Doty MM, Pierson R, Applebaum S. How health insurance design affects access to care and costs, by income, in eleven countries. Health Aff (Millwood). 2010;29(12):2323-34.

7 Organization for Economic Cooperation and Development. Health at a glance 2012. Paris: OECD; 2012.
8 Ellis RP, Miller MM. Provider payment methods and incentives. In: Carrin G, editor. Health systems policy, finance, and organization. Amsterdam: Elsevier Academic Press; 2009. p. 322-9.

9 Dranove D, White WD. Agency and the organization of health care delivery. Inquiry. 1987;24(4):405-15.

10 Busse R, Quentin W. Moving towards transparency, efficiency, and quality in hospitals: conclusions and recommendations. In: Busse $\mathrm{R}$, Geissler A, Quentin W, Wiley MM, editors. Diagnosis Related Groups in Europe: moving towards transparency, efficiency, and quality in 
hospitals. Maidenhead (UK): Open University Press; 2011. p. 149-74.

11 Kobel C, Thuillez J, Bellanger MM, Aavikso A, Pfeiffer K. Diagnosis Related Group (DRG) systems and similar Patient Classification Systems in Europe. In: Busse R, Geissler A, Quentin W, Wiley MM, editors. Diagnosis Related Groups in Europe: moving towards transparency, efficiency, and quality in hospitals. Maidenhead (UK): Open University Press; 2011. p. 37-58.

12 Quentin W, Scheller-Kreinsen D, Geissler A, Busse R. Appendectomy and diagnosis-related groups (DRGs): patient classification and hospital reimbursement in 11 European countries. Langenbecks Arch Surg. 2012;397(2):317-26.

13 Scheller-Kreinsen D, Quentin W, Geissler A, Busse R. Breast cancer surgery and diagnosis-related groups (DRGs): patient classification and hospital reimbursement in 11 European countries. Breast. 2012 Dec. [Epub ahead of print].

14 Quentin W, Rätto H, Peltola M, Busse R, Häkkinen U. Acute myocardial infarction and diagnosisrelated groups: patient classification and hospital reimbursement in 11 European countries. Eur Heart J. 2013 Jan 30. [Epub ahead of print].

15 Cots F, Chiarello P, Salvador X, Quentin W. DRG-based hospital payment: intended and unintended consequences. In: Busse R, Geissler A, Quentin W, Wiley MM, editors. Diagnosis Related Groups in Europe: moving towards transparency, efficiency and quality in hospitals. Maidenhead (UK): Open University Press; 2011. p. 75-92.

16 Fetter J, Shin Y, Freeman JL, Averill RF, Thompson JD. Case mix definition by diagnosis-related groups. Med Care. 1980;18(2 Suppl):iii, 1-53.

17 Centers for Medicare and Medicaid Services. Hospital inpatient prospective payment systems for acute care hospitals and the long-term care hospital prospective payment system and FY 2012 rates. Fed Regist. 2011; 76:51476-846.

18 Rheinisch-Westfälisches Institut für Wirtschaftsforschung.

Mengenentwicklung und

Mengensteuerung stationärer Leistungen. Essen: RWI; 2012. German.

19 Scheller-Kreinsen D, Quentin W, Busse R. DRG-based hospital payment systems and technological innovation in 12 European countries. Value Health. 2011;14(8):1166-72.

20 Schreyögg J, Stargardt T, Tiemann $\mathrm{O}$, Busse R. Methods to determine reimbursement rates for diagnosis related groups (DRG): a comparison of nine European countries. Health Care Manag Sci. 2006;9(3):215-23.

21 Tan SS, van Ineveld BM, Redekop K, Hakkaart-van Roijen L. The Netherlands: The Diagnose Behandeling Combinaties. In: Busse R, Geissler A, Quentin W, Wiley MM, editors. Diagnosis Related Groups in Europe: moving towards transparency, efficiency and quality in hospitals. Maidenhead (UK): Open University Press; 2011. p. 425-46.

22 Department of Health. Best practice tariffs. London: DoH; 2011.

23 Department of Health. Commissioning for Quality and Innovation (CQUIN): 2013-14 guidance. London: DoH; 2013.

24 Murray R. Setting hospital rates to control costs and boost quality: the Maryland experience. Health Aff (Millwood). 2009;28(5):1395-405.

25 Jencks SF, Williams MV, Coleman EA. Rehospitalizations among patients in the Medicare fee-for-service program. N Engl J Med. 2009; 360(14):1418-28.

26 Hilgers S. DRG-Vergütung in deutschen Krankenhäusern. Auswirkungen auf Verweildauer und Behandlungsqualität. Wiesbaden: Gabler; 2011. German.

27 Center for Medicare and Medicaid
Innovation. Bundled Payments for Care Improvement Initiative [Internet]. Baltimore (MD): Centers for Medicare and Medicaid Services; 2011 Aug 23 [cited 2013 Mar 7]. (Fact Sheet). Available from: http:// innovation.cms.gov/Files/factsheet/Bundled-Payments-FactSheet.pdf

28 Wynn BO, Beckett MK, Hilborne LH, Scott M, Bahney B. Evaluation of severity adjusted DRG system. Santa Monica (CA): RAND Corporation; 2007.

29 Busse R, Geissler A, Mason A, Or Z, Scheller-Kreinsen D, Street A, editors. Diagnosis-Related Groups in Europe (EuroDRG): do they explain variation in hospital costs and length of stay across patients and hospitals? Health Econ. 2012;21(Supplement 2):1-140.

30 Institut für das Entgeldsystem im Krankenhaus. Abschlussbericht Weiterentwicklung des G-DRGSystems für das Jahr 2004. Siegburg: InEK; 2003. German.

31 Institut für das Entgeldsystem im Krankenhaus. Vorschlagsverfahren zur Einbindung des medizinischen, wissenschaftlichen und weiteren Sachverstandes bei der Weiterentwicklung des G-DRGSystems für das Jahr 2012. Siegburg: InEK; 2011. German.

32 Sutton M, Nikolova S, Boaden R, Lester H, McDonald R, Roland M. Reduced mortality with hospital pay for performance in England. N Engl J Med. 2012;367(19):1821-28.

33 Currie C, Partridge M, Plant F, Roberts J, Wakeman R, William A. National Hip Fracture Database: national report 2012. London: The Database; 2012.

34 Busse R, Nimptsch U, Mansky T. Measuring, monitoring, and managing quality in Germany's hospitals. Health Aff (Millwood). 2009; 28(2):w294-304. DOI: 10.1377/ hlthaff.28.2.w294. 


\section{ABOUT THE AUTHORS: WILM QUENTIN, DAVID SCHELLER-KREINSEN, MIRIAM BLUMEL, ALEXANDER GEISSLER \& REINHARD BUSSE}

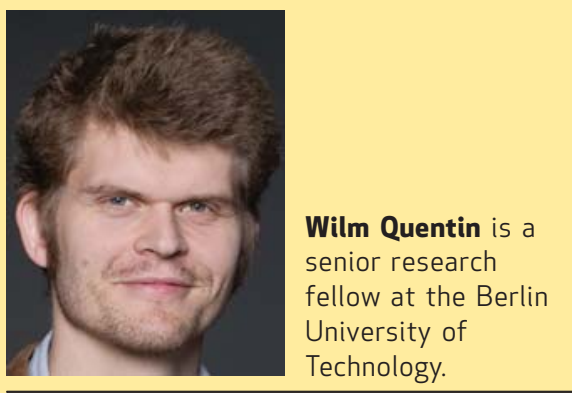

In this month's Health Affairs, Wilm Quentin and coauthors describe how a number of European countries imported and expanded upon Medicare's inpatient prospective payment system, which originated the use of diagnosisrelated groups, or DRGs. These countries evolved different design options that are generally more detailed than Medicare's system; have ceilings to limit the volume of care, unlike in Medicare; and are usually broader in scope, including physician salaries and readmissions. The authors propose that these European systems, discussed in more detail in the article, could suggest potential innovations for DRG-based hospital payment in the United States.

Quentin is a senior research fellow in the Department of Health Care Management at the Berlin University of Technology and a research fellow of the European Observatory on Health Systems and Policies. He is also a managing editor of Health Policy and the European Observatory's Health Systems in Transition series. He earned a master's degree in health policy, planning, and financing from the London School of Hygiene and Tropical Medicine and the London School of Economics and Political Science (LSE), and a medical degree from the University of Marburg.

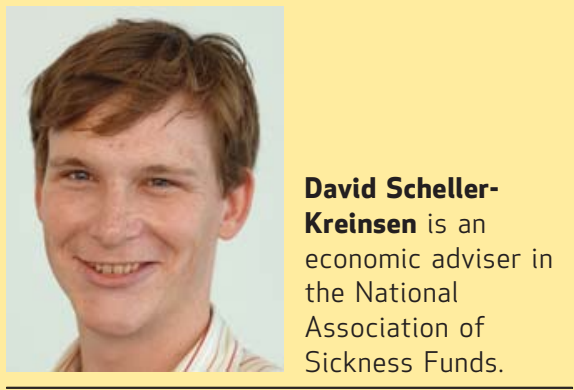

David Scheller-Kreinsen is an economic adviser in the Hospital Division of the National Association of Sickness Funds in Germany. Previously, he was a managing editor of Health Policy and a guest editor of Health Economics. He received a bachelor's degree in industrial relations from LSE; a master's degree in public policy from the Hertie School of Governance, Berlin; and a doctorate in health economics from the Berlin University of Technology.

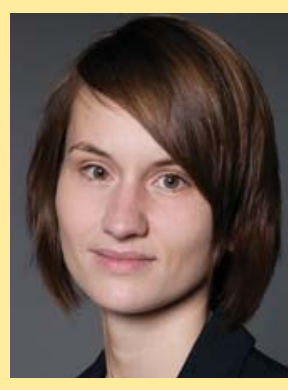

Miriam Blümel is a research fellow and doctoral candidate at the Berlin University of Technology.

Miriam Blümel is a research fellow and doctoral candidate in the Department of Health Care Management at the Berlin University of Technology. She received a master's equivalent degree in sociology from the Free University of Berlin.

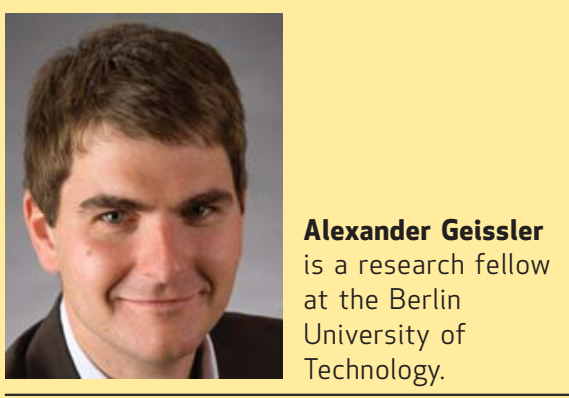

Alexander Geissler is a research fellow in the Department of Health Care Management at the Berlin University of Technology. He received a master's equivalent degree in economics and engineering from that university.

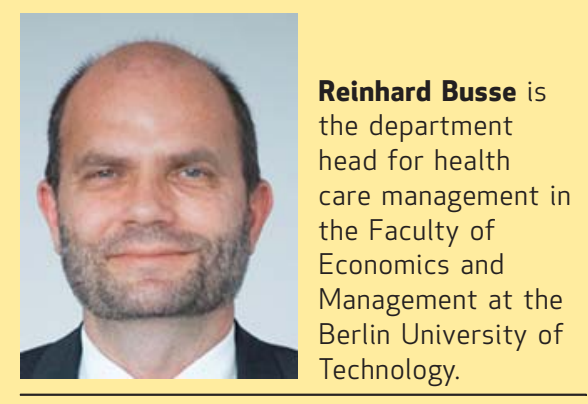

Reinhard Busse is a professor and the department head for health care management in the Faculty of Economics and Management at the Berlin University of Technology. $\mathrm{He}$ is also the associate head of research policy and director of the Berlin hub of the European Observatory.

Additionally, Busse is the editorin-chief of Health Policy and a series editor of the Observatory's Health Systems in Transition. Between 2009 and 2011 he coordinated the EuroDRG project. He earned a master's degree in public health from the Hannover Medical School and a medical degree from the University of Marburg. 